\title{
Immersive Experience during Covid-19: The Mediator Role of Alternative Assessment in Online Learning Environment
}

\author{
https://doi.org/10.3991/ijim.v15i18.24541 \\ Mohd Hanafi Azman Ong ${ }^{1(\mathbb{凶})}$, Norazlina Mohd Yasin², Nur Syafikah Ibrahim ${ }^{1}$ \\ ${ }^{1}$ Universiti Teknologi MARA (Kampus Segamat), Johor, Malaysia \\ ${ }^{2}$ Universiti Teknologi Malaysia (UTMSPACE), Johor, Malaysia \\ napieong@uitm. edu.my
}

\begin{abstract}
The Covid-19 epidemic has transformed the educational scene, hence altering the learning experience of students. The traditional face-to-face classroom has evolved into a synchronous online mode that requires minimum technology literacy. Their capability for absorption of information may be compromised under massive scenarios encountered throughout the acquisition of information. This article examines the function of alternative assessment in structured learning activities with the goal of deconstructing their learning competence and fostering complex interaction. The research focuses on the relationship between numerous aspects and students' online learning experiences, notably during the pandemic. An online survey was performed with 312 respondents who utilised the Blackboard online learning platform and a PLS-SEM analysis indicated that an alternative assessment mediated the relationship of learning readiness, student engagement, and student motivation toward student learning experience simultaneously. In conclusion, our study reinforces the vital need of addressing the mediator role of alternative assessment to enhance the learning experience and, hence, success in online classes.
\end{abstract}

Keywords — online learning, learning experience, immersive experience, Covid-19, mediator analysis

\section{$1 \quad$ Introduction}

As the Covid-19 epidemic struck in 2020, education delivery shifted away from conventional face-to-face instruction and toward online instruction. Restriction of movement during the lockdown has accelerated the rise of digital learning, having a major effect on the learning experience of remote learners. The "new normal" climate necessitates that academics at Higher Education Institutions (HEIs) rethink previously held beliefs. Academics at HEIs should reassess teaching approaches other than conventional lectures in light of the "new normal." Their preparedness for blended learning, however, is very low due to difficulties faced when merging teachings into fully online classrooms. Additionally, though today's children have a range of learning styles, they are all proficient in digital literacy [1]. The contrast between conventional 
teaching techniques that are "dynamic and fluid" and online pedagogy has further hindered their learning experience. Blended learning integrates online and offline instruction to foster deep and meaningful learning while maintaining the principles associated with conventional academic institutions [2]. With advanced technology, this form of learning may enhance the efficacy and efficiency of learning experiences [3]. Online instructors, on the other hand, have been slow to adjust to changes in students' learning techniques and dynamics. Embracing students' learning experiences enables online instructors to assess the quantity of knowledge students have acquired and their ability to apply course-related material.

The majority of research on e-learning examines learning models from three perspectives: (1) efficacy and student happiness, (2) convenience, and (3) if they complement traditional learning. To begin, research evaluating the aspects that contribute to the effectiveness of an online learning experience as a new learning media system have been conducted. It has been found that online learning media are more likely to provide students with gratifying services [4]. Second, prior research has shown that online education facilitates learners' access to educational resources.

Because of the increasing demand for internet access, the creation of subject-based learning resources has been facilitated, culminating in the production of final goods in the form of e-materials [5]. It is possible that students with a wide range of goals, motivations, and preferences may exhibit surprising behaviours when engaging with the materials, which may further impair their learning performance. A large number of studies have looked at how online learning may supplement some of the best qualities of both traditional in person instruction as well as the advancement of communication via digital technology, especially in the setting of distant learning. The methodology was proven to be capable of providing students with information on how to give practical and realistic possibilities, similar to the blended learning method [6]. As a result of technology and communication developments, online learning trends are gaining traction without compromising the key characteristics of face-to-face interaction.

\section{$2 \quad$ Literature review}

\subsection{Student's learning readiness and learning experience}

Learning readiness is a state of mind that is constantly prepared to adopt a new manner of learning, notably via the use of technology. Online education has been found to increase students' readiness for learning in Malaysian higher education, which has a positive effect on their learning experience [7]. The critical factors that fueled the need for online learning management have been shown to be highly dependent on students' attitudes toward knowledge acquisition, particularly self-learning [8], self-efficacy [9,10], learner control [11], and self-directed learning [12]. The transition from face-to-face to online or blended learning has enhanced student engagement and perceived learning, cooperative learning and academic motivation, academic accomplishment and continuance, as well as satisfaction and self-confidence [13,11]. Students with a high level of self-regulation; an essential component in e-learning preparation can maintain an online learner's ongoing effort and accurately forecast their learning result $[14,15,16]$. 


\subsection{Student engagement}

Instructors should consider student engagement while creating high-quality material for delivery of teaching and learning in an online learning environment. It is well established that engagement necessitates unique techniques to promote information acquisition that is connected to students' comprehension [17,18]. Scholars have argued for a strong connection between student engagement and the specific use of a MOOC video [19], a blackboard learning management system [20], course-specific learning analytics and nudging [21] and blended learning [22,23,24,25]. Given the critical nature of the reciprocal connection between engagement and learning, it's predictable that the connection has been explored across a range of elements, measurement approaches, and domains [26]. An interactive learning experience may reintroduce structure, purpose, and excitement to classroom work, which has lately been recognized as a critical aspect of learning performance.

Students' high levels of engagement and interest in attendance and punctuality indicate that student engagement has a substantial influence on students' equal amount of responsibility for their development, learning, and accomplishment, and engagement [27]. Teachers who established high standards, implemented evidence-based techniques, and created engaging learning experiences were successful in harnessing their autistic students' engagement behavior. The strategies improved their students' abilities and emotions, as well as their learning engagement, learning process, and learning experience, all of which influenced their learning results. Students who participated in the preparation, presentation, and response to questions from the judges were better equipped to manage such circumstances in the future [28].

\subsection{Student motivation}

Students' drive to study should be perseverance in the realm of educational science and technology, where complexity is defined by the relationship between teaching and learning [29]. However, their motivation often decreases while online study. Certain measures have been shown to be effective in increasing students' motivation and learning experience $[30,31,32]$, including applied learning approaches, instructional materials motivating survey within the use of self-directed learning materials, collaborative problem-based learning experience, and classroom feedback [33].

Motivated learners thrive on achievement and have faith in their capacity for performance, perseverance, and innovation. Despite the overwhelming use of web-based learning and teaching to aid students' learning, students' motivation should remain constant throughout their learning experience. Their willingness to study a web-based learning technology influenced their satisfaction with their online courses, perceived quality, perceived relevance, competence, accomplishment, and learning experience $[34,35]$. They may access learning materials in advance and prepare for the next class session using their preferred modes of teaching, which increases their perceived level of learning. Indeed, their educational experience is characterized by self-regulated learning, which includes motivation, emotion, engagement, pleasure, and instructional strategies. 
However, online learning presents difficulties for untrained self-regulated learners [35]. Thus, to assure the efficiency of online learning, students must exhibit specific characteristics such as a sense of autonomy, superiority, control, curiosity, and engagement, as well as a strong connection and a focus on learning. Self-regulation occurs in a variety of ways throughout the learning process. High authenticity and dynamism are two traits that define an admirable individual [36]; these traits illustrate the achievement motivation for online learning [37].

\subsection{Alternative assessment as mediator variable}

Alternative evaluations have been frequently employed as a catalyst for technology adoption to help learners better comprehend technological functions and their implications for their intended learning goals and skills. Alternative assessment is defined as a technique that has a higher formative and motivating value for students [38]. Alternative evaluations have been frequently employed as a catalyst for technology adoption to help learners better comprehend technological functions and their implications for their intended learning goals and skills. The evaluation emphasizes students' innovative ideas and efforts; this may be seen as a kind of creative self-expression and an alternate method of evaluating the project-based learning process [26,39]. Essentially, performance and reflection are the two components of the learning experience that are regarded fundamental for students to have a meaningful online learning experience.

Individuals within the educational sector have varying perspectives on how assessment procedures should be implemented. Cognitive assessment, performance assessment, and portfolio evaluation are all included in the setting; performance assessment was shown to have the most impact on alternative evaluation. Additionally, other evaluation techniques used in practice include open-ended inquiries, displays, demonstrations, hands-on experimentation, computer simulation, and portfolios. Given the evidence that authentic alternative assessment is critical for effective online learning, assessment may be implemented via resources, learning tools, motivation, and assessment technologies [40]. Additionally, this indicates that rubrics and student portfolios achieve parity in terms of alternative evaluation in online environments. As a result, including alternate evaluations is critical for optimizing the learning experience. To the researcher's knowledge, relatively few studies have been undertaken on the influence of alternate evaluation methods on the learning experience associated with e-learning. In educational performance evaluations, especially those involving e-learning, an alternative assessment is seen as a distinct concept.

\section{Methodology}

A quantitative analysis and survey techniques were utilised to examine the impact of various assessment mediator variables on students' learning preparedness, engagement, motivation, and learning experience [41,42]. A total of 312 respondents who utilised the Blackboard online learning platform were chosen using a nonprobability sample 
methodology that combines judgemental and convenience sampling. This strategy allows for the decrease of respondents' selection bias. To ensure that all inquiries were addressed by respondents, an electronic media data gathering approach was utilised.

In terms of data analysis, structural equation modelling with partial least squares (i.e. PLS-SEM) estimation multivariate data technique was used since the sample size can be considered as relatively small, and the conceptual framework for this study can be considered complex (consisting of two mediator paths simultaneously) [43,44]. PLS-SEM can also be considered as an optimal statistical data analysis tool for handling second-order measurement variables; the analysis allows the use of latent variable score (LVS) from the first-order measurement variable analysis as the indicator score for the second-order measurement variable $[45,46]$. The significance test in the PLS-SEM analysis was computed by using the bootstrapping method, which is considered more robust than the conventional t-test method $[45,46]$. Therefore, 5000 replications of samples were computed to obtain reliable results for the empirical t-statistics and bias corrected (i.e. BCa) bootstrap [43].

The following method for determining the mediating impact was utilised for evaluating the effect of mediation $[47,48]$ :

1. A full mediation effect was seen if the route from the independent to the dependent variable did not show statistical significance was statistically significant because of the indirect influence.

2. A partial mediation effect occurs when the path from the independent variable to the dependent variable is significant and the indirect impact is substantial, which indicates that the mediating effect was only partially effective.

\section{$4 \quad$ Analysis and result}

\subsection{Measurement model analysis}

In accordance with Table 1, all the indicators that were utilized for assessing the constructs that are being addressed in the first-order measurement model satisfy the minimal threshold value for at least .70 factor loading in the first-order model. The AVE index for each construct was more than .50, and that both reliability tests (i.e., composite reliability and Cronbach's Alpha) for each targeted construct were greater than .70 $[43,49]$. They demonstrate that each variable in the first-order measurement model is possible to consider it to have the best unidimensional validity, which is consistent with previous results $[43,44]$. 


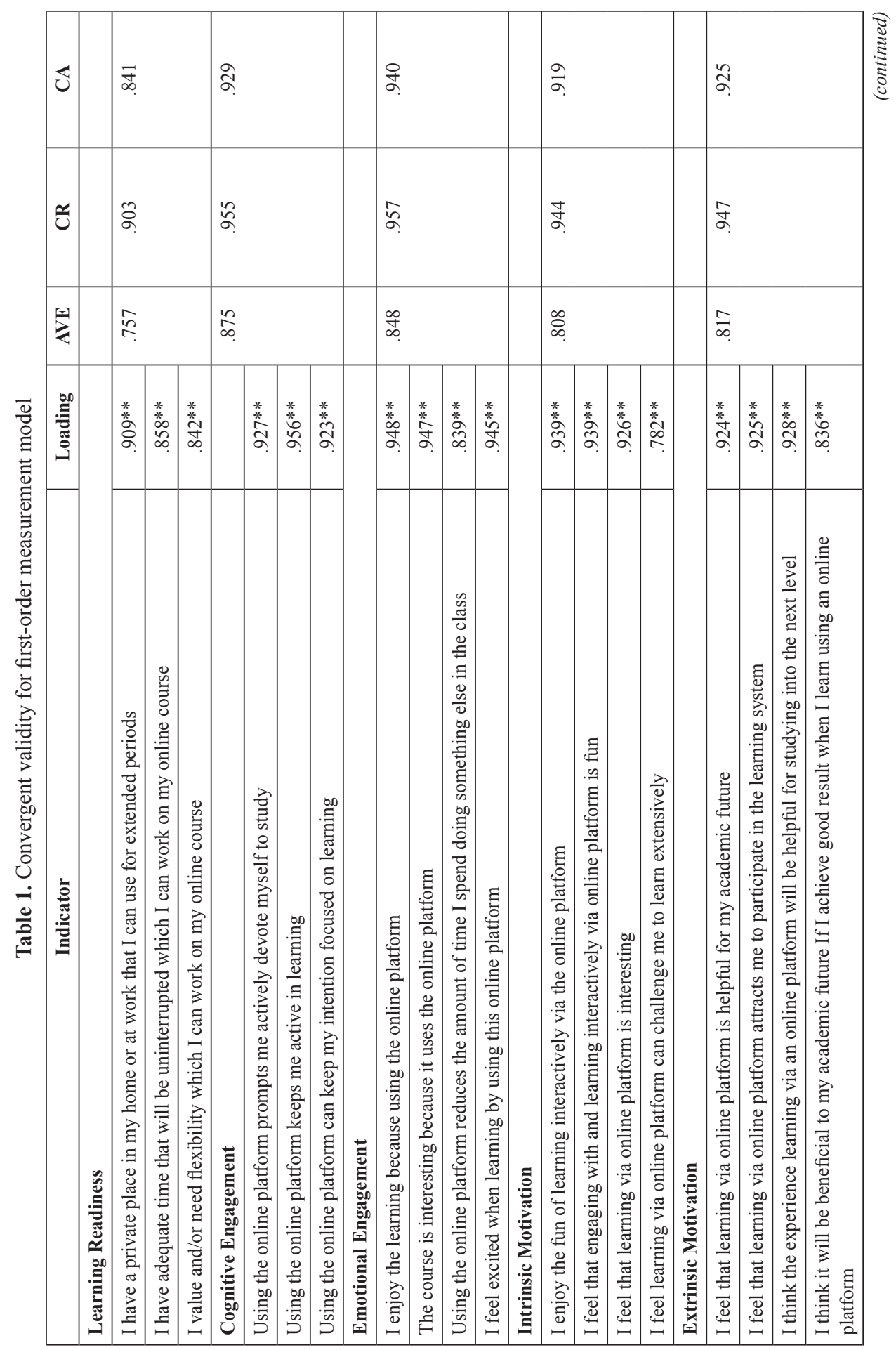




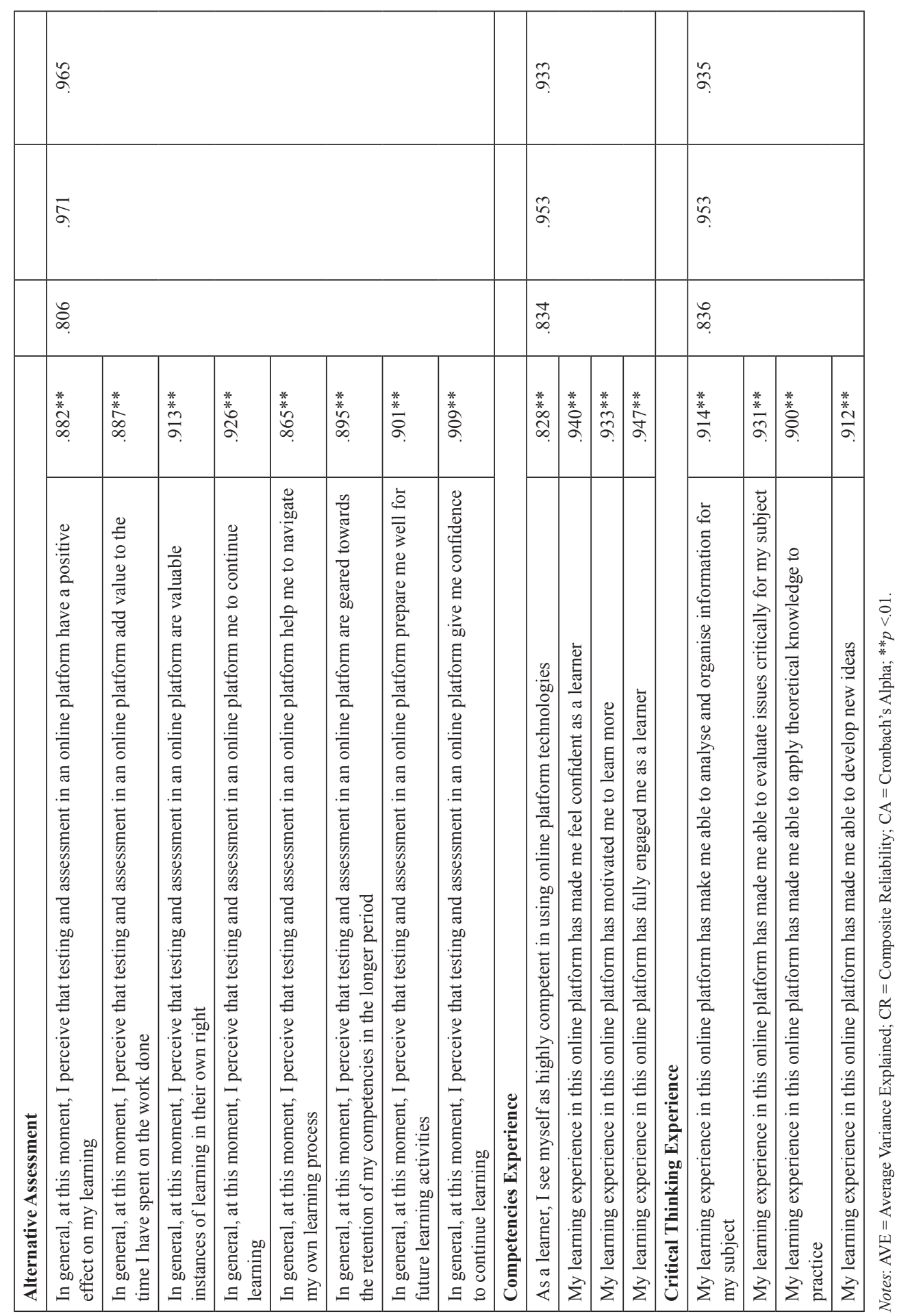


As for the discriminant validity of each latent variable in this measurement, each of the HTMT ratio values was below .90, which means that each latent variable fully discriminates from the others (Table 2). As a consequence, the set of indicators that were used to evaluate a specific construct were accurate in their measurement of that construct [50].

Table 2. HTMT discriminant analysis for first-order measurement model

\begin{tabular}{|l|c|c|c|c|c|c|c|c|}
\hline & $\mathbf{( 1 )}$ & $\mathbf{( 2 )}$ & $\mathbf{( 3 )}$ & $\mathbf{( 4 )}$ & $\mathbf{( 5 )}$ & $\mathbf{( 6 )}$ & $\mathbf{( 7 )}$ & $\mathbf{( 8 )}$ \\
\hline$(1)$ & - & & & & & & & \\
\hline$(2)$ & $.719^{* *}$ & - & & & & & & \\
\hline$(3)$ & $.739^{* *}$ & $.819^{* *}$ & - & & & & & \\
\hline$(4)$ & $.743^{* *}$ & $.855^{* *}$ & $.854^{* *}$ & - & & & & \\
\hline$(5)$ & $.758^{* *}$ & $.860^{* *}$ & $.856^{* *}$ & $.869^{* *}$ & - & & & \\
\hline$(6)$ & $.730^{* *}$ & $.815^{* *}$ & $.824^{* *}$ & $.821^{* *}$ & $.815^{* *}$ & - & & \\
\hline$(7)$ & $.819^{* *}$ & $.816^{* *}$ & $.811^{* *}$ & $.815^{* *}$ & $.794^{* *}$ & $.871^{* *}$ & - & \\
\hline$(8)$ & $.836^{* *}$ & $.761^{* *}$ & $.750^{* *}$ & $.794^{* *}$ & $.777^{* *}$ & $.872^{* *}$ & $.820^{* *}$ & - \\
\hline
\end{tabular}

Notes: (1) = Learning Readiness; (2) = Cognitive Engagement; (3) = Emotional Engagement; (4) = Intrinsic Motivation; $(5)$ Extrinsic Motivation; $(6)=$ Alternative Assessment; $(7)=$ Competencies Experience; $(8)=$ Critical Thinking Experience; ${ }^{*} p<.01$

Because the first-order measurement model passed the convergent and discriminant validity requirements, the LVS scores computed at this step may be utilised as a result of the indicators' performance within the framework of the second-order polynomial measurement model. As shown in Table 3, the LVS ratings for Cognitive Engagement and Emotional Engagement were intended to assess the Student Engagement construct, while the LVS ratings for Social Engagement were intended to test the Student Engagement construct. The Intrinsic Motivation score on the LVS and Extrinsic Motivation constructs were also used as indicators for measuring the Student Motivation construct, as shown in Table 4. The same procedure was also applied for measuring the Learning Experience construct. The LVS scores for Competencies Experience and Critical Thinking Experience were used as indicators for measuring the Learning Experience construct. The indications for the Learning Readiness and Alternative Assessment constructs, on the other hand, are more specific and were retained as those from the first-order measurement model throughout this analysis step, since these two constructs lacked a dimension construct. 
Table 3. Convergent validity for second-order measurement model

\begin{tabular}{|c|c|c|c|c|}
\hline Indicator & Loading & AVE & CR & CA \\
\hline \multicolumn{2}{|l|}{ Learning Readiness } & & & \\
\hline $\begin{array}{l}\text { I have a private place in my home or at work that I can use for } \\
\text { extended periods }\end{array}$ & $.909 * *$ & \multirow[t]{3}{*}{.757} & \multirow[t]{3}{*}{.903} & \multirow[t]{3}{*}{.841} \\
\hline $\begin{array}{l}\text { I have adequate time that will be uninterrupted which I can work } \\
\text { on my online course }\end{array}$ & $.858 * *$ & & & \\
\hline $\begin{array}{l}\text { I value and/or need flexibility which I can work on my online } \\
\text { course }\end{array}$ & $.842 * *$ & & & \\
\hline \multicolumn{2}{|l|}{ Student Engagement } & & & \\
\hline${ }^{a}$ Cognitive Engagement & $.964 * *$ & \multirow[t]{2}{*}{.930} & \multirow[t]{2}{*}{.964} & \multirow[t]{2}{*}{.925} \\
\hline${ }^{a}$ Emotional Engagement & $.965^{* *}$ & & & \\
\hline \multicolumn{2}{|l|}{ Student Motivation } & & & \\
\hline antrinsic Motivation & $.966^{* *}$ & \multirow[t]{2}{*}{.932} & \multirow[t]{2}{*}{.965} & \multirow[t]{2}{*}{.927} \\
\hline${ }^{\mathrm{a} E x t r i n s i c ~ M o t i v a t i o n ~}$ & $.965^{* *}$ & & & \\
\hline \multicolumn{2}{|l|}{ Alternative Assessment } & & & \\
\hline $\begin{array}{l}\text { In general, at this moment, I perceive that testing and assessment } \\
\text { in an online platform have a positive effect on my learning }\end{array}$ & $.882 * *$ & \multirow[t]{8}{*}{.806} & \multirow[t]{8}{*}{.971} & \multirow[t]{8}{*}{.965} \\
\hline $\begin{array}{l}\text { In general, at this moment, I perceive that, testing and } \\
\text { assessment in an online platform add value to the time I have } \\
\text { spent on the work done }\end{array}$ & $.887^{* *}$ & & & \\
\hline $\begin{array}{l}\text { In general, at this moment, I perceive that testing and assessment } \\
\text { in an online platform are valuable instances of learning in their } \\
\text { own right }\end{array}$ & $.913 * *$ & & & \\
\hline $\begin{array}{l}\text { In general, at this moment, I perceive that testing and assessment } \\
\text { in online platform me to continue learning }\end{array}$ & $.926^{* *}$ & & & \\
\hline $\begin{array}{l}\text { In general, at this moment, I perceive that testing and assessment } \\
\text { in an online platform help me to navigate my own learning } \\
\text { process }\end{array}$ & $.865^{* *}$ & & & \\
\hline $\begin{array}{l}\text { In general, at this moment, I perceive that testing and assessment } \\
\text { in an online platform are geared towards the retention of my } \\
\text { competencies in the longer period }\end{array}$ & $.895^{* *}$ & & & \\
\hline $\begin{array}{l}\text { In general, at this moment, I perceive that testing and assessment } \\
\text { in an online platform prepare me well for future learning } \\
\text { activities }\end{array}$ & $.901 * *$ & & & \\
\hline $\begin{array}{l}\text { In general, at this moment, I perceive that testing and assessment } \\
\text { in an online platform give me confidence to continue learning }\end{array}$ & $.909 * *$ & & & \\
\hline \multicolumn{2}{|l|}{ Learning Experience } & & & \\
\hline aCompetencies Experience & $.965^{* * *}$ & \multirow[t]{2}{*}{.930} & \multirow[t]{2}{*}{.964} & \multirow[t]{2}{*}{.925} \\
\hline${ }^{\mathrm{a} C} \mathrm{Critical}$ Thinking Experience & $.964 * *$ & & & \\
\hline
\end{tabular}

Notes: ${ }^{\text {a }}$ This is using Latent Variable Score estimation; $\mathrm{AVE}=$ Average Variance Explained; $\mathrm{CR}=$ Composite Reliability; $\mathrm{CA}=$ Cronbach's Alpha; $* * p<.01$. 
On the other hand, the minimum threshold value of .70 for factor loading, as well as the minimum threshold values for AVE, composite reliability, and Cronbach's Alpha for each construct, are met in the second-order measurement model, as shown in Table 3. As a result of these findings, each construct in the second-order measurement model may be deemed to have adequate unidimensional validity $[43,44]$.

Table 4. HTMT discriminant analysis for second-order measurement model

\begin{tabular}{|l|c|c|c|c|c|}
\hline & $\mathbf{( 1 )}$ & $\mathbf{( 2 )}$ & $\mathbf{( 3 )}$ & $\mathbf{( 4 )}$ & (5) \\
\hline$(1)$ & - & & & & \\
\hline$(2)$ & $.761^{* *}$ & - & & & \\
\hline$(3)$ & $.776^{* *}$ & $.812^{* *}$ & - & & \\
\hline$(4)$ & $.730^{* *}$ & $.825^{* *}$ & $.846^{* *}$ & - & \\
\hline$(5)$ & $.763^{* *}$ & $.806^{* *}$ & $.839^{* *}$ & $.815^{* *}$ & - \\
\hline
\end{tabular}

Notes: (1) = Learning Readiness; (2) = Student Engagement; (3) = Student Motivation; (4) = Alternative Assessment; (5) $=$ Learning Experience; $* * p<.01$.

If we look at how well the second-order measurement model discriminates among itself, each latent construct completely distinguishes itself from the others since each HTMT ratio was less than 90. (See Table 4). Because of this, the set of indicators that were utilized to assess the construct in the second-order measurement model were accurate in measuring the construct in concern [50].

\subsection{Structural model analysis}

The structural model analysis indicates that the all independent constructs - Learning Readiness, Student Engagement, and Student Motivation-were able to provide 83\% the proportion of variance that can be explained toward the Alternative Assessment mediator construct. Simultaneously, a combination of the three independent constructs with the mediator construct was successful in explaining about 78.5 percent of the variance explained toward the Learning Experience. Both the effect size as well as the predictive relevance size of the Learning Readiness dimension are substantial in relation to the Alternative Assessment mediator construct, indicating that it is a good predictor of the latter. Contrary to this, the impact sizes of the Student Engagement and Student Motivation constructs on the mediator construct are moderate, and their predictive relevance sizes are also moderate (Table 5). In the same way, when compared to the Learning Experience mediator construct, the Alternative Assessment mediator construct was able to provide a high magnitude of the impact and the size of predictive significance. The analysis also indicates that the effect size and the predictive relevance size for the three independent constructs toward the dependent construct were categorised as a small effect. Hence, the analysis of effect size together with predictive relevance of the structural model may be regarded to have fulfilled the very minimal requirements for a PLS model, which the magnitude of this impact is greater than zero. 
Table 5. Structural model

\begin{tabular}{|l|c|c|c|c|c|c|l|}
\hline \multicolumn{1}{|c|}{ Path } & B & t-Statistic & $\boldsymbol{p}$-Value & $\begin{array}{c}\mathbf{9 5 \%} \text { BCa } \\
\text { Bootstrap }\end{array}$ & $f^{2}$ & $q^{2}$ & \multicolumn{1}{|c|}{ Remark } \\
\hline LRE $\rightarrow$ ALE & 0.529 & $11.410^{* *}$ & $<.01$ & $(0.433,0.614)$ & .206 & .193 & Large \\
\hline $\mathrm{STE} \rightarrow$ ALE & 0.296 & $5.248^{* *}$ & $<.01$ & $(0.190,0.409)$ & .119 & .086 & Medium \\
\hline $\mathrm{STM} \rightarrow$ ALE & 0.175 & $3.069^{* *}$ & .002 & $(0.071,0.294)$ & .110 & .076 & Medium \\
\hline $\mathrm{ALE} \rightarrow$ LEX & 0.486 & $6.779^{* *}$ & $<.01$ & $(0.344,0.624)$ & .187 & .172 & Large \\
\hline $\mathrm{LRE} \rightarrow$ LEX & 0.129 & $2.424 *$ & .015 & $(0.031,0.237)$ & .021 & .005 & Small \\
\hline $\mathrm{STE} \rightarrow$ LEX & 0.144 & $2.261^{*}$ & .024 & $(0.024,0.275)$ & .026 & .009 & Small \\
\hline $\mathrm{STM} \rightarrow$ LEX & 0.192 & $2.729^{* *}$ & .006 & $(0.055,0.330)$ & .037 & .012 & Small \\
\hline
\end{tabular}

Notes: $\mathrm{LRE}=$ Learning Readiness $; \mathrm{STE}=$ Student Engagement $\mathrm{STM}=$ Student Motivation; ALE $=$ Alternative Assessment; LEX $=$ Learning Experience; $\beta=$ Standardized Beta Coefficient; $f^{2}=$ Effect Size; $q^{2}=$ Predictive Relevance; $* p<.05 ; * * p<.01$

According to the results of the cause and effect study, all of the relevant paths were positive statistically significant at a level of 95 percent confidence level (Table 5). All of the t-statistic values were greater than 1.96, which indicates statistical significance at the 5 percent level of significance. Following the $\mathrm{BCa}$ (Bootstrapping confidence interval analysis), the results are similarly consistent with the t-statistical analysis: the 95 percent confidence interval does not include the value 0 .

\subsection{Mediating analysis}

The mediating analysis (Table 6) indicates that the alternative assessment statistically and simultaneously mediated the relationship of LRE $\rightarrow$ LEX, STE $\rightarrow$ LEX and STM $\rightarrow$ LEX. This is because the indirect effect coefficients are significant at $5 \%$ level of error (t-statistics $>1.96$ ), and the $95 \%$ BCa bootstrapping confidence interval does not include the zero value. Since all the direct effects of this structural model (i.e. LRE $\rightarrow$ LEX, STE $\rightarrow$ LEX and STM $\rightarrow$ LEX) are statistically significant, the mediator paths of $\mathrm{LRE} \rightarrow \mathrm{ALE} \rightarrow \mathrm{LEX}, \mathrm{STE} \rightarrow \mathrm{ALE} \rightarrow \mathrm{LEX}$ and $\mathrm{STM} \rightarrow \mathrm{ALE} \rightarrow$ LEX can be classified partially mediated. Figure 1 and Figure 2 show the results of the analysis using PLS-SEM algorithm.

Table 6. Indirect effect assessment

\begin{tabular}{|l|c|c|c|c|}
\hline \multicolumn{1}{|c|}{ Indirect Path } & IEC & t-Statistic & $\boldsymbol{p}$-Value & $\mathbf{9 5 \% ~ B C a ~ B o o t s t r a p ~}$ \\
\hline $\mathrm{LRE} \rightarrow \mathrm{ALE} \rightarrow \mathrm{LEX}$ & 0.257 & $6.075^{* *}$ & $<.01$ & $(0.182,0.345)$ \\
\hline $\mathrm{STE} \rightarrow \mathrm{ALE} \rightarrow \mathrm{LEX}$ & 0.144 & $4.069^{* *}$ & $<.01$ & $(0.081,0.219)$ \\
\hline $\mathrm{STM} \rightarrow \mathrm{ALE} \rightarrow \mathrm{LEX}$ & 0.085 & $2.670^{* *}$ & .008 & $(0.033,0.158)$ \\
\hline
\end{tabular}

Notes: LRE $=$ Learning Readiness; STE $=$ Student Engagement; STM $=$ Student Motivation; ALE = Alternative Assessment; LEX $=$ Learning Experience; IEC = Indirect Effect Coefficient; ${ }^{* *} p<.01$. 


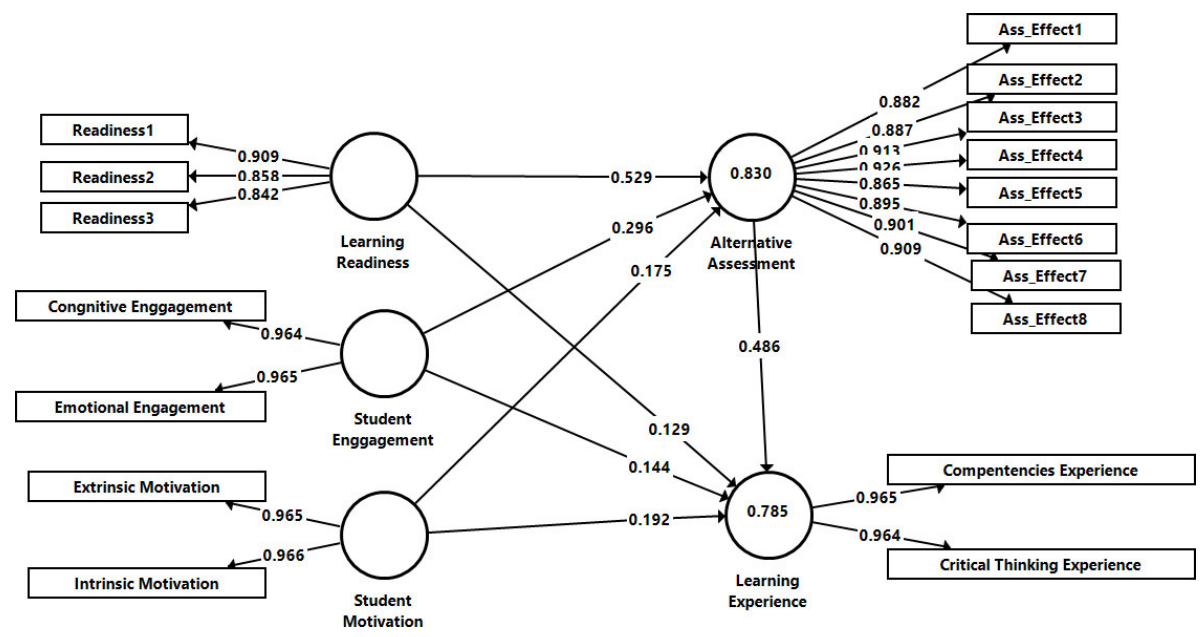

Fig. 1. PLS SEM analysis output for loading and path coefficient values

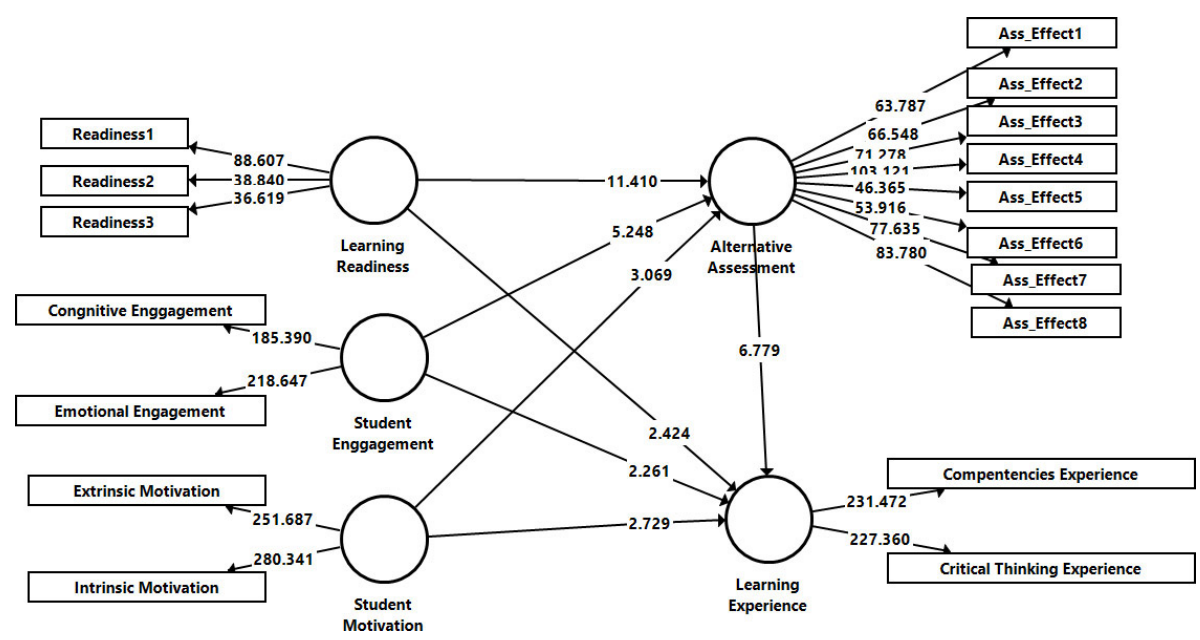

Fig. 2. PLS SEM analysis output for t-statistic values via bootstrapping analysis

\section{$5 \quad$ Conclusions and discussion}

As many HEIs invest in developing their capacity and capacities in digital education as a means of achieving a competitive edge throughout internationalisation, the results of this research may be utilised to further our understanding of learning theory. Learners from diverse backgrounds may accept a variety of learning styles, depending on the teaching techniques used to maximise learning efficacy. Thus, the results indicate numerous suggestions to HEIs about the development and classification of an education 
ecosystem that spans cultures, teaching styles, and efficacy characteristics. The findings may contribute to improving the quality of education and generating revenue via digital learning in an open system.

Based on the findings, learning readiness, student engagement, and motivation all have a significant role in determining the quality of an online learning experience. Alternative assessment was recognised as the mediator function, making it a priority. The new learning environment for remote students is favourable, since younger generations are willing to study, participate, and interact with their teachers, despite the fact that alternative evaluations were seldom used prior to the epidemic. Students' options have risen as a result of the quickly growing digital learning environment. Thus, HEIs should embrace digitalization of education and use it to advance and increase knowledge, notably via distance-learning programmes. Adult learners need a variety of teaching methodologies in online distance learning (ODL) programmes, as well as a variety of learning settings as moderators, which leads in a unique learning experience that may be the subject of future study.

Additionally, the digitisation of education has increased prospects for international cooperation in academic programmes by attracting more students from different nations. Due to the variety of learning preferences and styles throughout cultures, the learning process has become more open and adaptable. This has resulted in an increase in online educational methodologies. Online education in a digital education system requires high-quality learning outcomes and experiences, highlighting the need of understanding how learners absorb information. By presenting and sharing knowledge in the manner in which learners perceive it, they will have a greater opportunity to choose instructors who match their learning styles, therefore gaining control over their learning. Thus, while making online learning choices, it is crucial to evaluate the learner's experience with e-learning systems, since this is considering the benefits to the learner's overall learning well-being and academic achievement.

\section{References}

[1] Yasin, N.M., Ong, M.H.A., \& Aziz, N.N.A. (2020). Attitude as Mediator of Technical Usage Self-Efficacy, Online Communication Self-Efficacy, Technology Access and Online Media on the Blended Learning Readiness. International Journal of Advanced Science and Technology, 29 (6s), 713-724.

[2] Syakur, A. (2020). The effectiveness of English learning media through Google Classroom in Higher Education. Britian International of Linguistics Arts and Education (BIoLAE) Journal, 2(1), 475-483. https://doi.org/10.33258/biolae.v2i1.218

[3] Ichssan, I.Z., \& Rahmayanti, H. (2020). HOTSTEP: Revised Anderson's Taxonomy in environmental learning of Covid-19. European Journal of Educational Research, 9(3), 1257-1265. https://doi.org/10.12973/eu-jer.9.3.1257

[4] Putranti, N. (2016). Cara membuat media pembelajaran online menggunakan edmodo. Jurnal Pendidikan Informatika dan Sains, 2(2), 139-147.

[5] Ibrahim, D.S.M., \& Febriani, Y. (2018). Pengembangan E-Materi berbasis mata kuliah pada pembelajaran jarak jauh (E-Learning). Jurnal DIDIKA: Wahana Ilmiah Pendidikan Dasar, 4(2), 1-16. https://doi.org/10.29408/didika.v4i2.1170 
[6] Prayitno, A. (2015). Pemanfaatan sistem informasi perpustakaan digital berbasis website untuk para penulis. Indonesia Journal on Software Engineering (IJSE), 1(1), $28-37$.

[7] Adams, D., Suminto, B., Mohamed, A., \& Mohamad Noor, N.S. (2018). E-learning readiness among students of diverse backgrounds in a leading Malaysian Higher Educational Institution. Malaysian Journal of Learning and Instruction, 15(2), 227-256. https://doi. org $/ 10.32890 / \mathrm{mjli2} 2018.15 .2 .9$

[8] Herguner, G., Son, S.B., Son, S.H., \& Donmez, S. (2020). The effect of online learning attitudes of University on their Online Learning Readiness. The Turkish Online Journal of Educational Technology, 19(4), 102-110.

[9] Hui Lin, H., Lin, S., Hsuan Yeh, C., \& Wang, Y.S. (2015). Measuring mobile learning readiness: scale development and validation. Internet Research, 26(1), 265-287. https://doi. org/10.1108/IntR-10-2014-0241

[10] Fang, J., \& Teng, M. (2021). Discussion on the improvement of online learning ability of higher vocational college students by online games and the existing problems. Journal of Physics: Conference Series, 1915(4), 1-9. https://doi.org/10.1088/1742-6596/1915/4/042054

[11] Horzum, B.H., Ozturk, E., Bektas, M., Gungoren, O.C., \& Cakir, O. (2014). Secondary school students tablet computer acceptance and readiness: A structural equation modelling. Education and Science, 39(176), 81-93. https://doi.org/10.15390/EB.2014.3500

[12] Geng, S., Law, K.M.Y., \& Niu, B. (2019). Investing self-directed learning and technology readiness in blended learning environment. International Journal of Educational Technology in Higher Education, 16(1), 1-22. https://doi.org/10.1186/s41239-019-0147-0

[13] Demir, K.Z., \& Horzum, M.B. (2013). Relationship between online learning readiness and structure and interaction of online learning students. Educational Sciences: Theory and Practise, 13(1), 1792-1797.

[14] Sahoo, S. (2016). Finding self-directed learning readiness and fostering self-directed learning through weekly assessment of self-directed learning topics during undergraduate clinical training in ophthalmology. International Journal of Applied and Basic Medical Research, 6(3), 1-5. https://doi.org/10.4103/2229-516X.186959

[15] Wang, W., \& Zhan, J. (2020). The relationship between English Language Learner characteristics and online self-regulation: A structural equation modeling approach. Sustainability, 12(7), 1-25. https://doi.org/10.3390/su12073009

[16] Mishra, D.S., Agarwal, A., \& Kolekar, S.V. (2021). Dynamic Identification of Learning Styles in MOOC Environment Using Ontology Based Browser Extension. International Journal of Emerging Technologies in Learning, 16(12). 65-93. https://doi.org/10.3991/ijet. v16i12.21789

[17] Zhan, Z., \& Mei, H. (2013). Academic self-concept and social presence in face to face and online learning, perceptions and effects on student's learning achievement and satisfaction across environments. Computer and Education, 69(1), 131-138. https://doi.org/10.1016/j. compedu.2013.07.002

[18] Ramirez, D.M., \& Gillig, S. (2018). Computer technology and twitter for online learning and student engagement. Journal of Multidisciplinary Research, 10(1/2), 137-153. https:// doi.org/10.4324/9780429444654-9

[19] Guo, P.J., Kim, J., \& Rubin, R. (2014). How video production affects student engagement: an empirical study of MOOC videos. Proceedings of the 1st ACM Conference on Learning at Scale, pp. 41-50. https://doi.org/10.1145/2556325.2566239

[20] Ncubukezi, T., \& Daramola, O. (2020). Influence of e-learning via blackboard on the learning experiences of late bloomers in information technology. European Conference on e-learning, Kidmore End (Oct 2020). DOI:10.34190/EEL.20.017. 
[21] Lawrence, J., Brown, A., Redmond, P., \& Basson, M. (2019). Engaging the disengaged: Exploring the use of course-specific learning analytics and nudging to enhance online student engagement. Student Success, 10(2), 47-58. https://doi.org/10.5204/ssj.v10i2.1295

[22] Dzuiban, C.D., Hartman, J.L., Cavanagh, T.B., \& Moskal, P.D. (2011). Blended courses as drivers of institutional transformation. In A. Kitchenham (Ed), Blended learning across disciplines: Model for implementation (pp. 17-37). Hershey, PA: IGI Global. https://doi. org/10.4018/978-1-60960-479-0.ch002

[23] Henrie, C.R., Bodily, R., Manwaring, K.C., \& Graham, C.R. (2015). International Review of Research in Open and Distributed Learning, 16(3), 131-155. https://doi.org/10.19173/ irrodl.v16i3.2015

[24] Bouilheres, F., Le le Thi Viet, H., McDonald, S., Nkhoma, C., \& Jandug-Montera, L. (2020). Defining student learning experience through blended learning. Education and Information Technologies, 25(4), 3049-3069. https://doi.org/10.1007/s10639-020-10100-y

[25] Ouchaouka, L., Laouina, Z., Moussetad, M., Talbi, M., \& Elamrani, N. (2021). The Effectiveness of a Learner-Centered Pedagogical Approach with Flipped Pedagogy and Digital Learning Environment in Higher Education Feedback on a Cell Biology Course. International Journal of Emerging Technologies in Learning, 16(12). https://doi.org/10.3991/ijet. $\underline{\mathrm{v} 16 \mathrm{i} 12.19125}$

[26] Mathews, N., Sriratanaviriyakul, N., Hiep, P.C., \& Lam, T.K. (2014). Examining the mediating role of learning engagement, learning process and learning experience on the learning outcomes through localized real case studies. Education and Training, 56(4), 287-302. https://doi.org/10.1108/ET-01-2013-0005

[27] Mohandas, P., \& Vinitwatanakhun, A. (2020). Student engagement and students' equity in Thai engagement in the Thai context. The New English Teacher, 14(1), 33-42.

[28] Grau, S.L., \& Akin, R. (2011). Experiential learning for nonbusiness students: Students engagement using a marketing trade show. Marketing Education Review, 21(1), 69-78. https://doi.org/10.2753/MER1052-8008210110

[29] Hauze, S., \& Marshall, J. (2020). Validation of the instructional materials motivating survey: measuring student motivation to learn via mixed reality nursing education simulation. International Journal on E-Learning, 19(1), 49-64.

[30] Jones, B.D., Epler, C.M., Mokri, P., Bryant, L.H., \& Paretti, M.C. (2013). The effects of a collaborative problem-based learning experience on students' motivation in Engineering Capstone Courses. Interdisciplinary Journal of Problem Based Learning, 7(2), 34-71. https://doi.org/10.7771/1541-5015.1344

[31] Cho, M.H., \& Heron, M.L. (2015). Self-regulated learning: the role of motivation, emotion and use of learning strategies in students' learning experiences in a self paced online mathematics course. Distance Education, 36(1), 80-99. https://doi.org/10.1080/01587919 .2015 .1019963

[32] Trolian, T., \& Jach, E.A. (2020). Engagement in college and university applied learning experiences and student's academic motivation. Journal of Experiential Education, 43(3), 317-335. https://doi.org/10.1177/1053825920925100

[33] Gan, Z., He., J., Liu, F., \& Xie, Q. (2020). Classroom feedback practice and students' learning motivation: experiences of English as a foreign language (EFL) students. Applied Language Learning, 30(1-2), 18-40.

[34] Kim, K.J., \& Frick, T.W. (2011). Changes in student motivation during online learning. Journal of Educational Computing Research, 44(1), 1-23. https://doi.org/10.2190/ EC.50.1.a; https://doi.org/10.2190/EC.44.1.a

[35] Cho, M.H., \& Heron, M.L. (2015). Self-regulated learning: the role of motivation, emotion, and use of learning strategies in students learning experiences in a self-paced online mathematics course. Distance Education, 36(1), 80-99. https://doi.org/10.1080/01587919.2015.1019963 
[36] Salah Eldin, K., Al-Shafie, A.I., Abdel Halim, S., \& Otoom, S. (2015). Relationship between the quality of blended learning experience, self-regulated learning, and academic achievement of medical students: a path analysis. Advances $n$ Medical Education and Practices, 6(2015), 27-34. https://doi.org/10.2147/AMEP.S75830

[37] Cigdem, H., \& Ozturk, M. (2016). Critical components of online learning readiness and their relationships with learner achievement. Turkish Online Journal of Distance Education, 17(2), 98-109. https://doi.org/10.17718/tojde.09105

[38] Williams, P. (2014). Squarring the circle: a new alternative to alternative-assessment. Teaching in Higher Education, 19(5), 565-577. https://doi.org/10.1080/13562517.2014.882894

[39] Smith, S. (2016). (Re) counting meaningful learning experiences: Using student-created reflective videos to make invisible learning visible during PjBL experiences. Interdisciplinary Journal of Problem based Learning, 10(1), 16. DOI: https://doi.org/10.7771/1541-5015.1541

[40] Alotaibi, S.R. (2021). A Novel Framework of Success Using of E-Assessment During Corona Pandemic. International Journal of Emerging Technologies in Learning, 16(12). https://doi.org/10.3991/ijet.v16i12.22063

[41] Creswell, J.W. (2014). Educational Research: Planning, Conducting and Evaluating Quantitative and Qualitative Research (4th ed.). London: Pearson New International Edition.

[42] Saunders, M., Lewis, P., \& Thornhill, A. (2009). Research Method for Business Students (5th ed.). New York: Prentice Hall Publications.

[43] Hair, J.F., Hult, G.T.M., Ringle, C.M., \& Sarstedt, M. (2017). A primer on partial least squares structural equation modeling. (PLS-SEM) (2nd ed.). Thousand Oaks: Sage Publications.

[44] Ong, M.H.A., \& Puteh, F. (2017). Quantitative Data Analysis: Choosing Between SPSS, PLS, and AMOS in Social Science Research. International Interdisciplinary Journal of Scientific Research, 3(1), 14-25.

[45] Hair, J.F., Sarstedt, M., Ringle, C.M., \& Mena, J.A. (2012). An assessment of the use of partial least squares structural equation modeling in marketing research. Journal of the Academy Marketing Science, 40(3), 414-433. https://doi.org/10.1007/s11747-011-0261-6

[46] Henseler, J., \& Chin, W.W., (2010). A comparison of approaches for the analysis of interaction effects between latent variables using partial least squares path modeling. Structural Equation Modeling 17(1), 82-109. https://doi.org/10.1080/10705510903439003

[47] Zhao, X., Lynch, J.G.J., \& Chen, Q. (2010). Reconsidering Baron and Kenny: Myths and truth about mediation analysis. Journal of Consumer Research, 17, 197-206. https://doi. org $/ 10.1086 / 651257$

[48] Iacobucci, D., Saldanha, N., \& Deng, X. (2007). A meditation on mediation: Evidence that structural equation models perform better than regression. Journal of Consumer Psychology, 7(2), 140-154. https://doi.org/10.1016/S1057-7408(07)70020-7

[49] Hair, J.F., Ringle, C.M., \& Sarstedt, M. (2011). PLS-SEM: Indeed a silver bullet. Journal of Marketing Theory and Practice, 19(2), 139-151. https://doi.org/10.2753/ MTP1069-6679190202

[50] Henseler, J., Ringle, C.M., \& Sarstedt, M. (2015). A new criterion for assessing discriminant validity in variance-based structural equation modelling. Journal of the academy of marketing science, 43(1), 114-135. https://doi.org/10.1007/s11747-014-0403-8 


\section{Authors}

Mohd Hanafi Azman Ong, Department of Statistics and Decision Sciences, Faculty of Computer and Mathematical Sciences, Universiti Teknologi MARA (Kampus Segamat), Segamat, Johor, Malaysia. E-mail: napieong@uitm.edu.my.

Norazlina Mohd Yasin, School of Professional and Continuing Education, Universiti Teknologi Malaysia (UTMSPACE), Skudai, Johor, Malaysia. E-mail: norazlina@, utmspace.edu.my.

Nur Syafikah Ibrahim, Department of Computer Sciences, Faculty of Computer and Mathematical Sciences, Universiti Teknologi MARA (Kampus Segamat), Segamat, Johor, Malaysia. E-mail: nursyafikah@uitm.edu.my.

Article submitted 2021-06-04. Resubmitted 2021-07-29. Final acceptance 2021-07-29. Final version published as submitted by the authors. 